Supporting Information

\title{
Superionic Halogen-Rich Li-Argyrodites Using In-Situ Nanocrystal Nucleation and Rapid Crystal Growth
}

Wo Dum Jung, ${ }^{\dagger,+}$ Ji-Su Kim, ${ }^{\dagger}$ Sungjun Choi, ${ }^{\dagger}$ Seongmin Kim, ${ }^{\dagger+\neq}$ Minjae Jeon, ${ }^{\dagger}$ Hun-Gi Jung, ${ }^{\S}$ Kyung Yoon Chung, ${ }^{\S}$ Jong-Ho Lee, ${ }^{\dagger}$ Byung-Kook Kim, ${ }^{\dagger}$ Jong-Heun Lee, ${ }^{\star}$ and Hyoungchul Kim *, ${ }^{\dagger}$

${ }^{\dagger}$ Center for Energy Materials Research, Korea Institute of Science and Technology, Seoul 02792, Republic of Korea.

tDepartment of Materials Science and Engineering, Korea University, Seoul 02841, Republic of Korea.

${ }^{\S}$ Center for Energy Storage Research, Korea Institute of Science and Technology, Seoul 02792, Republic of Korea.

\section{AUTHOR INFORMATION}

\section{Corresponding Author}

*E-mail: hyoungchul@kist.re.kr. 


\section{METHODS}

Sample preparation. High-purity starting materials $\left[\mathrm{Li}_{2} \mathrm{~S}, \mathrm{P}_{2} \mathrm{~S}_{5}\right.$, and $\mathrm{LiCl}$ (all from Aldrich)] were mixed in the appropriate molar ratio, after which the mixture was subjected to either the UMA (Pulverisette 6 Premium Line, Fritsch) or CMA (PM200, Retsch) milling method. UMA and CMA milling were applied at disk-rotation speeds of $700 \mathrm{rpm}$ for $6 \mathrm{~h}$ and $650 \mathrm{rpm}$ for $9 \mathrm{~h}$, respectively. The as-milled sample was ground into a fine powder using an agate jar and added to quartz tubes, after which the quartz tubes were heated to $550{ }^{\circ} \mathrm{C}$ for $25 \mathrm{~min}$ (ramping rate $=20^{\circ} \mathrm{C} \mathrm{s}^{-1}$, holding time $=20 \mathrm{~min}$ ) in an infrared lamp annealer (MILA-5000, Advance Riko). After annealing, the sample was rapidly cooled to $410^{\circ} \mathrm{C}$ at $10.7^{\circ} \mathrm{C} \mathrm{s}^{-1}$ and then slowly to $300^{\circ} \mathrm{C}$ at $0.8^{\circ} \mathrm{C} \mathrm{s}^{-1}$. After the temperature had dropped to $300^{\circ} \mathrm{C}$, the sample was quickly cooled to room temperature. The final product was obtained in ingot form, which was then ground into a fine solid electrolyte (SE) powder using an agate jar. All samples were prepared in a glove box (Arfilled, $\mathrm{O}_{2}$ and $\mathrm{H}_{2} \mathrm{O}<0.1 \mathrm{ppm}$ ), and a sealed container was used to suppress any sample degradation.

Sample characterization. The HRLA samples were subjected to XRD using a powder diffractometer (D8 Advance, Bruker) with $\mathrm{Cu}-\mathrm{K} \alpha$ radiation $(\lambda=1.540598 \AA)$. The powder specimen was placed on a silicon-zero background holder and covered with Kapton polyimide film to avoid dust and air contamination. Diffraction data were collected over the $10-90^{\circ} 2 \theta$ range in $0.02^{\circ}$ steps. Material crystallinity $\left(\chi_{\mathrm{c}}\right)$ was calculated as: $\chi_{\mathrm{c}}(\%)=\phi_{\text {argyrodite }} /\left(\phi_{\text {argyrodite }}+\phi_{\text {amorphous }}\right) \times$ $100,{ }^{1}$ where $\phi_{\text {argyrodite }}$ and $\phi_{\text {amorphous }}$ are the integrated areas of the Li-argyrodite and amorphous phase XRD peaks, respectively. The site occupancies and lattice parameters were obtained by Rietveld refinement (TOPAS, Bruker), which was performed using the split-Pearson VII analytic function with Chebyshev background. The Li-ion contents of all refinements were set to nominal values due to XRD resolution limitations. The sum of the $\mathrm{Cl}$ and $\mathrm{S}$ contents for the Wyckoff $4 a$ and $4 c$ site was set to unity in all refinements. The accuracies of the refined structural models were evaluated using the $\mathrm{R}_{\mathrm{wp}}$ and $\mathrm{R}_{\exp }$ fit indicators, as well as the goodness-of-fit (GoF). The crystalline structures of all HRLA samples were examined by TEM (Talos F200X, FEI). Each specimen was placed on a copper TEM grid coated with carbon film and a double tilt vacuum transfer holder (Model 648, GATAN) was used to avoid exposure to the atmosphere. ${ }^{31} \mathrm{P}$ NMR spectra were acquired on an NMR spectrometer (Model 400MR, Varian) operating with a 9.4 T field, and the VNMRJ system was used to acquire data. ${ }^{31} \mathrm{P}$ NMR studies were carried out at $161.97 \mathrm{MHz}$. The specimen was placed in a sealed rotor and mounted at the magic spinning angle $\left(54.74^{\circ}\right)$ in the NMR spectrometer. 
The spinning rate of rotor was calibrated to be about $6000 \mathrm{~Hz}$. Electrical conductivities were measured using a frequency response analyzer (Model 1260, Solartron) and electrochemical interface equipment (Model 1287, Solartron). Each powder was uniaxially pressed at $300 \mathrm{MPa}$ to form a 6-mm-diameter, 3-mm-thick pellet, which was examined by applying a voltage of $100 \mathrm{mV}$ in the $10^{3}$ to $10^{7} \mathrm{~Hz}$ frequency range. Electronic conductivities were measured by the Hebb-Wagner direct-current polarization method in an asymmetric Li/SE/Stainless-Steel cell. For the $\mathrm{Li}_{5.5} \mathrm{PS}_{4.5} \mathrm{Cl}_{1.5}$ UMA sample, cyclic voltammetry measurements of two asymmetric cells (Li/SE/SE-Carbon/Pt and Li/SE/Stainless-Steel) were performed with a scan rate of $0.1 \mathrm{mV} \mathrm{s}^{-1}$ at $25{ }^{\circ} \mathrm{C}$. Galvanostatic cycling tests of a symmetric $\mathrm{Li} / \mathrm{SE} / \mathrm{Li}$ cell was conducted at a current density of $0.5 \mathrm{~mA} \mathrm{~cm}-2$ and total capacity of $0.5 \mathrm{mAh} \mathrm{cm}^{-2}$ at $25^{\circ} \mathrm{C}$.

AIMD simulations. The Vienna ab-initio simulation package ${ }^{2}$ was used for all AIMD density functional theory calculations. A summary of the settings used to calculate the Li-ion migration characteristic of the HRLA structures is provided: The generalized gradient approximation was used to describe the exchange correlation energy. ${ }^{3}$ An energy cutoff of $280 \mathrm{eV}$ was used to describe the expanded plane wave functions. The site occupancies of the $4 a$ and $4 c$ sites and the lattice parameters for the $x=1.0$ and 1.5 unit-cell structures were set to the results obtained by Rietveld refinement. The gamma-point only $k$-point mesh was used in all calculation. AIMD simulations within the constant volume-temperature ensemble and the Nose-Hoover thermostat ${ }^{4}$ were used to determine the Li-ion probability densities in $\mathrm{Li}_{7-x} \mathrm{PS}_{6-x} \mathrm{Cl}_{x}$ at $x=1.0$ and 1.5. The AIMD calculation time and time step were set to $100 \mathrm{ps}$ and $2 \mathrm{fs}$, respectively. The $\mathrm{Li}$-ion probability densities and mean square displacements for the $\mathrm{Li}, \mathrm{S}$, and $\mathrm{Cl}$ ions were analyzed using the pymatgen-diffusion code as implemented in pymatgen. ${ }^{5}$

Fabricating and characterizing the cell. The composite cathode consisted of the active material $\left(\mathrm{LiNbO}_{3}\right.$ coated $\mathrm{LiNi}_{0.6} \mathrm{Co}_{0.2} \mathrm{Mn}_{0.2} \mathrm{O}_{2}, \mathrm{Nb}-\mathrm{NCM}$ ), the UMA-based $\mathrm{SE}\left(\mathrm{Li}_{5.5} \mathrm{PS}_{4.5} \mathrm{Cl}_{1.5}\right.$ ), and a conductive agent (vapor-grown carbon fiber, VGCF) in a 67.3:28.8:3.8 weight ratio. The areal mass loading of $\mathrm{Nb}-\mathrm{NCM}, \mathrm{Li}_{5.5} \mathrm{PS}_{4.5} \mathrm{Cl}_{1.5} \mathrm{SE}$, and VGCF in composite cathode is $17.15,7.39$, and $1.02 \mathrm{mg} \mathrm{cm}^{-2}$, respectively. The three powders and stainless-steel balls were placed in a stainless-steel bowl, with mixing conducted for 11 min using a vibration mixing mill (MM400, Retsch). To fabrication the cell, SE powder was fed into a mold and compressed at $192 \mathrm{MPa}$. The mixed composite cathode 
was placed on one side of the SE pellet, and an additional glass interlayer containing $\mathrm{LiI}^{6,7}\left[\left(0.75 \mathrm{Li}_{2} \mathrm{~S}-\right.\right.$ $\left.0.25 \mathrm{P}_{2} \mathrm{~S}_{5}\right)_{0.70}(\mathrm{LiI})_{0.30}$, LPS-LiI] was placed on the other side of pellet to enhance its mechanical properties. The two powders were pressed at $317 \mathrm{MPa}$, after which the SE side of the pellet (above the LiI-containing glass interlayer ${ }^{6,7}$ ) was covered with $\mathrm{Li}-\mathrm{In}$ powder (1:60 $\mathrm{wt} \%$; areal mass loading of $127.39 \mathrm{mg} \mathrm{cm}^{-2}$ ) (as the anode), and additionally pressed at $125 \mathrm{MPa}$. The four-layered pellet was assembled into a CR2032-type coin cell for electrochemical characterization. Rate capability testing was conducted in the $2.0-3.6 \mathrm{~V}$ (vs. In/InLi) voltage range at $25^{\circ} \mathrm{C}$ using a battery testing system. The current density at a $1 \mathrm{C}$-rate was set to $180 \mathrm{~mA} \mathrm{~g}^{-1}$, and the specific capacity was calculated based on the weight of NCM in the coin cell. Charging was carried out in constant-current/constantvoltage (CC-CV) mode, while discharging was performed in CC mode. A current density value of $20 \%$ in CC-mode was set as the terminal charging condition. Electrochemical performance was characterized at various current rates: 0.1, 0.2, and 0.5 C. For the charge/discharge cycling tests (listed in Figure S7), an all-solid-state battery (ASSB) cell without an additional glass interlayer was prepared: UMA-based $\mathrm{Li}_{5.5} \mathrm{PS}_{4.5} \mathrm{Cl}_{1.5} \mathrm{SE}$ powder $(0.04 \mathrm{~g})$ was fed into a mold and compressed at $192 \mathrm{MPa}$. The mixed composite cathode ( $0.02 \mathrm{~g}$ ) was placed on one side of the SE pellet, and then two powders were pressed at $317 \mathrm{MPa}$. Next, the SE side of the pellet was covered with Li-In powder (1:60 $\mathrm{wt} \% ; 0.1 \mathrm{~g}$ ), and a whole cell was additionally pressed at $125 \mathrm{MPa}$. All cell fabrication processes were carried out in an Ar-filled glove box, and the tests of these cells were conducted under normal atmospheric conditions, taking into account the sufficient sealing capability of the CR2032-type coin cell.

X-ray photoelectron spectroscopy (XPS; PHI 5000 VersaProbe, ULVAC PHI) was carried out by utilizing focused monochromatized $\mathrm{Al} \mathrm{K} \alpha$ radiation $(\mathrm{h} v=1486.6 \mathrm{eV}$ ). The obtained binding energy were calibrated with the Li $1 s$ peak to $55.6 \mathrm{eV}$. The cell fragments were attached on a sample holder in a dry Ar-filled glovebox and transferred to a chamber using a vacuum transfer vessel to avoid air exposure. The X-ray spot size was $100 \mu \mathrm{m} \times 100 \mu \mathrm{m}$, and the narrow scan pass energy was set to $58.7 \mathrm{eV}$. High resolution scans were collected in the Li $1 s, \mathrm{P} 2 p, \mathrm{O} 1 s, \mathrm{~S} 2 p, \mathrm{C}$ $1 s, \mathrm{Ni} 2 p, \mathrm{Co} 2 p, \mathrm{Mn} 2 p$ and $\mathrm{Cl} 2 p$ energy region with the pass energy. 


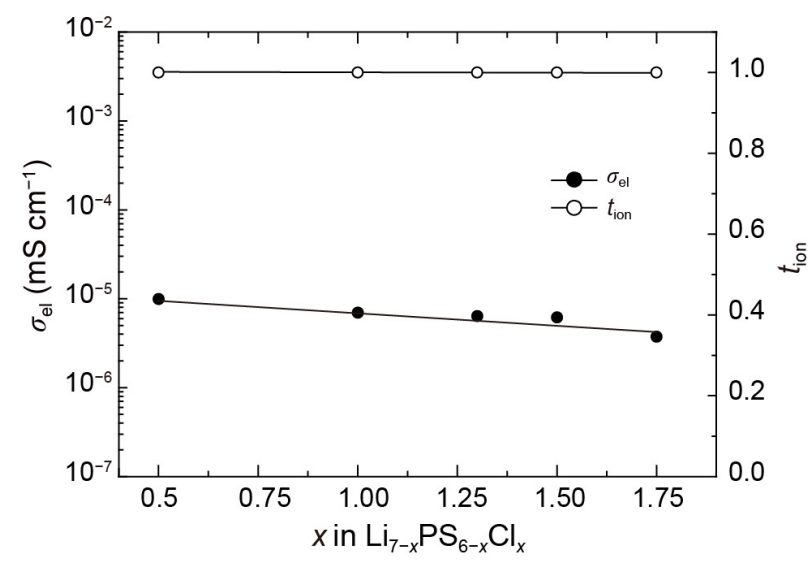

Figure S1. Variation of electronic conductivity $\left(\sigma_{\mathrm{el}}\right)$ and ion transference number $\left(t_{\text {ion }}\right)$ as a function of $\mathrm{Cl}$ content in as-annealed $\mathrm{Li}_{7-x} \mathrm{PS}_{6-x} \mathrm{Cl}_{x}$ samples at $25^{\circ} \mathrm{C}$. For $x=1.5$, its electronic conductivity and ion transference number are about $6.16 \times 10^{-6} \mathrm{mS} \mathrm{cm}^{-1}$ and 0.9999992 , respectively. These $\sigma_{\mathrm{el}}$ values are close to those of CMA-based $\mathrm{Li}_{6} \mathrm{PS}_{5} \mathrm{Cl}$ argyrodites $\left(\sigma_{\mathrm{el}}=3.0 \times 10^{-8}, 3.4 \times 10^{-9} \mathrm{~S} \mathrm{~cm}^{-1}\right)$ in the literature. ${ }^{8,9}$ 


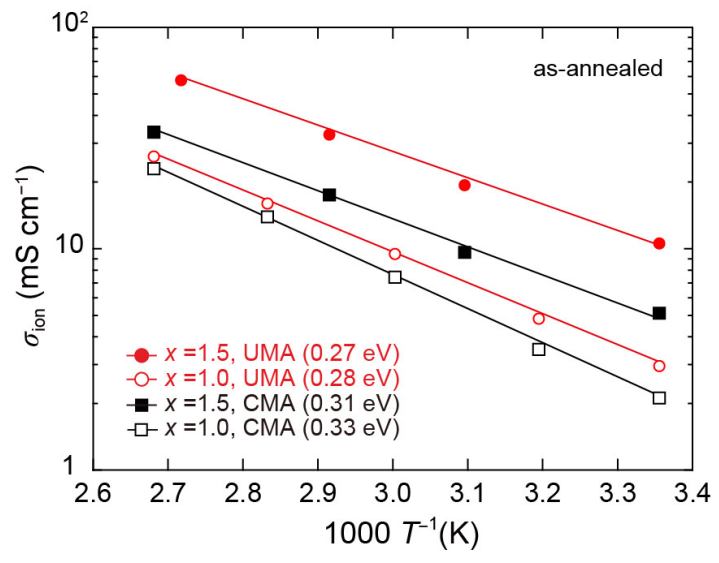

Figure S2. The Arrhenius relationship for Li-ion conductivity $\left(\sigma_{\text {ion }}\right)$ at $x=1.0$ and 1.5 using the ultimateenergy mechanical alloying (UMA) and conventional mechanical alloying (CMA) techniques, as a function of temperature. The UMA and CMA deliver the 49 and 37 G-force (GF) milling energy, respectively. Values in parentheses indicate the measured activation energies. 

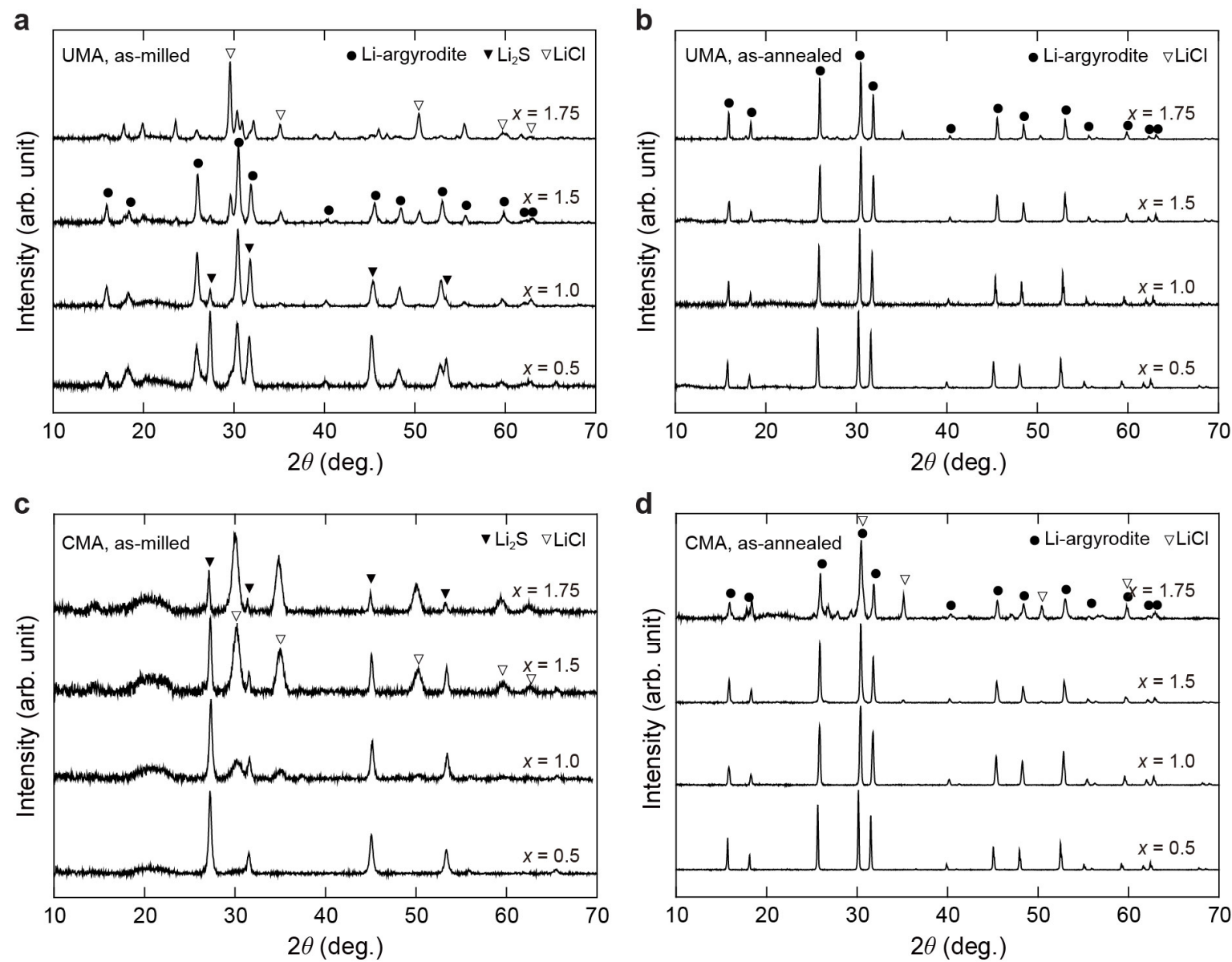

Figure S3. All XRD patterns of $\mathrm{Li}_{7-x} \mathrm{PS}_{6-x} \mathrm{Cl}_{x}(0.5 \leq x \leq 1.75)$ samples using UMA and CMA techniques before and after annealing. Reference XRD patterns of $\mathrm{Li}_{6} \mathrm{PS}_{5} \mathrm{Cl}$ (ICSD \#418490), $\mathrm{Li}_{2} \mathrm{~S}$ (ICSD \#642291), and LiCl (ICSD \#26909) are also shown. 

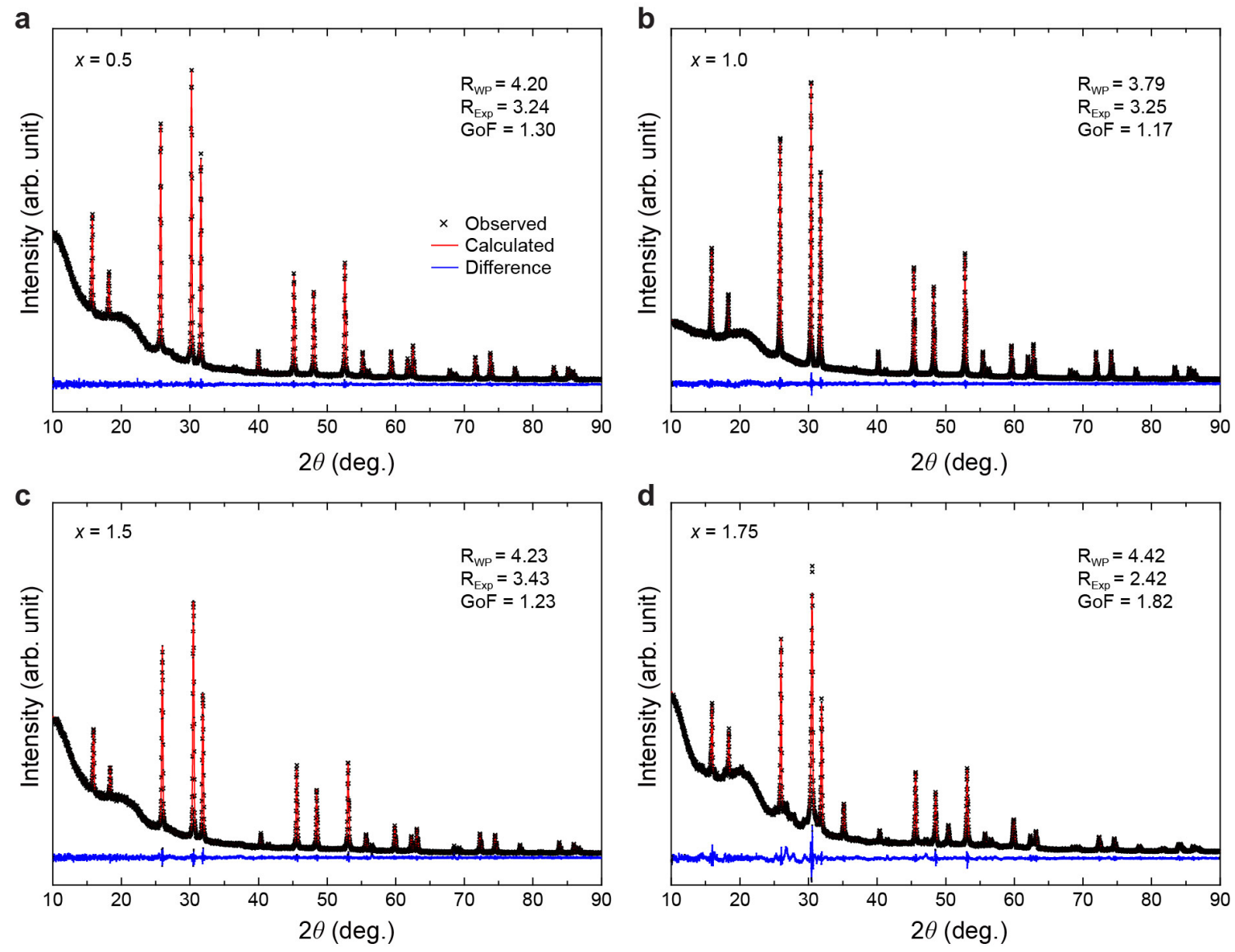

Figure S4. Rietveld refinement results of XRD patterns for as-annealed $\mathrm{Li}_{7-x} \mathrm{PS}_{6-x} \mathrm{Cl}_{x}(0.5 \leq x \leq 1.75)$ samples using UMA process. The accuracy of the refined structural models were evaluated using the $\mathrm{R}_{\mathrm{wp}}$ and $\mathrm{R}_{\exp }$ fit indicators, as well as the goodness-of-fit (GoF). 


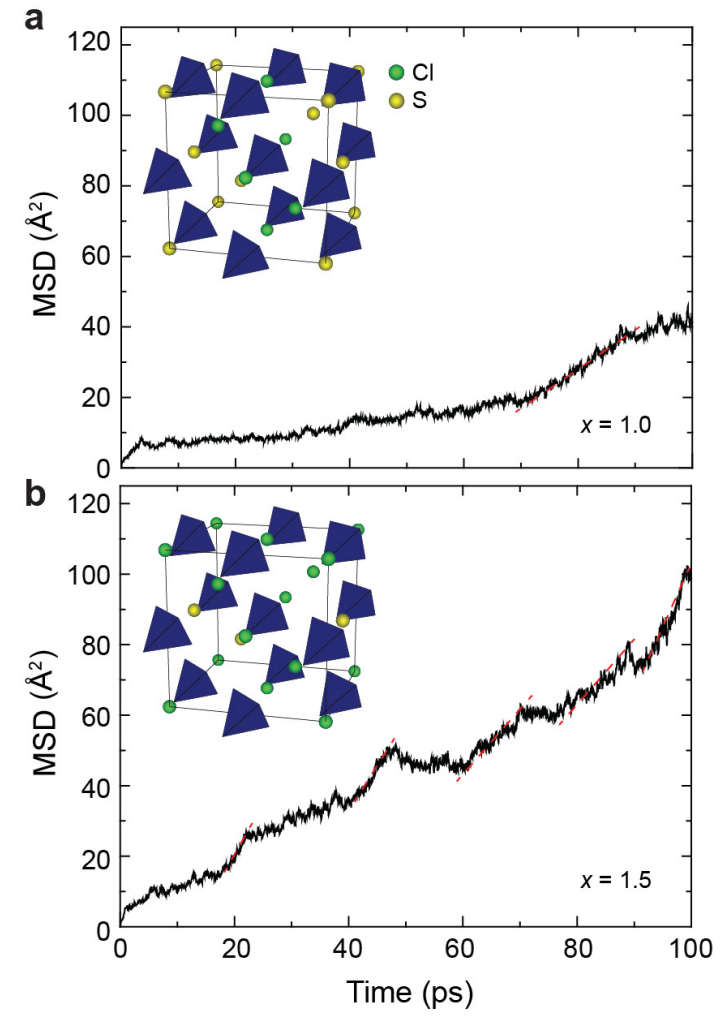

Figure S5. Mean-squares displacement (MSD) of Li-ions for (a) $x=1.0$ and (b) 1.5 as a function of simulation time. The red dotted guideline shows the general trend of directed superdiffusion for each. The inset image show the $\mathrm{Cl}$ configurations of each simulation structure. 


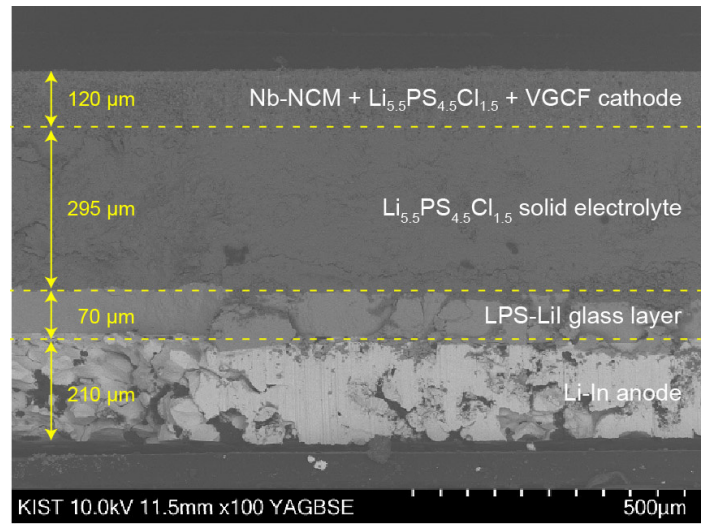

Figure S6. A cross-sectional SEM image of an ASSB cell used for rate capability performance tests (see Figure 4). 
a

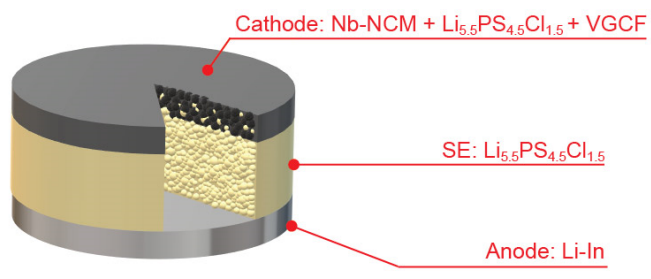

b
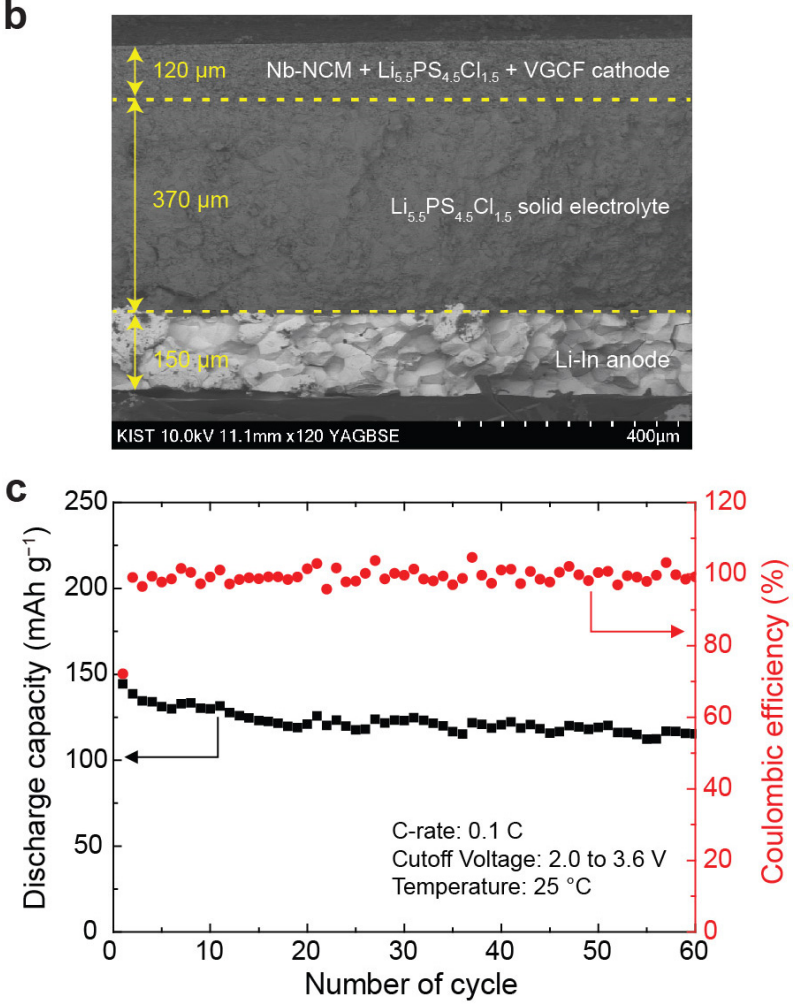

Figure S7. Cycling performance tests of an ASSB (Nb-NCM/Li $\left.{ }_{5.5} \mathrm{PS}_{4.5} \mathrm{Cl}_{1.5} / \mathrm{Li}-\mathrm{In}\right)$ cell with UMA-based $\mathrm{Li}_{5.5} \mathrm{PS}_{4.5} \mathrm{Cl}_{1.5} \mathrm{SE}$ at $25^{\circ} \mathrm{C}$ : (a) A schematic illustration and (b) cross-sectional SEM image of a cell. (c) Cycling profile for discharge capacity in a cell (0.1 C-rate). 
a
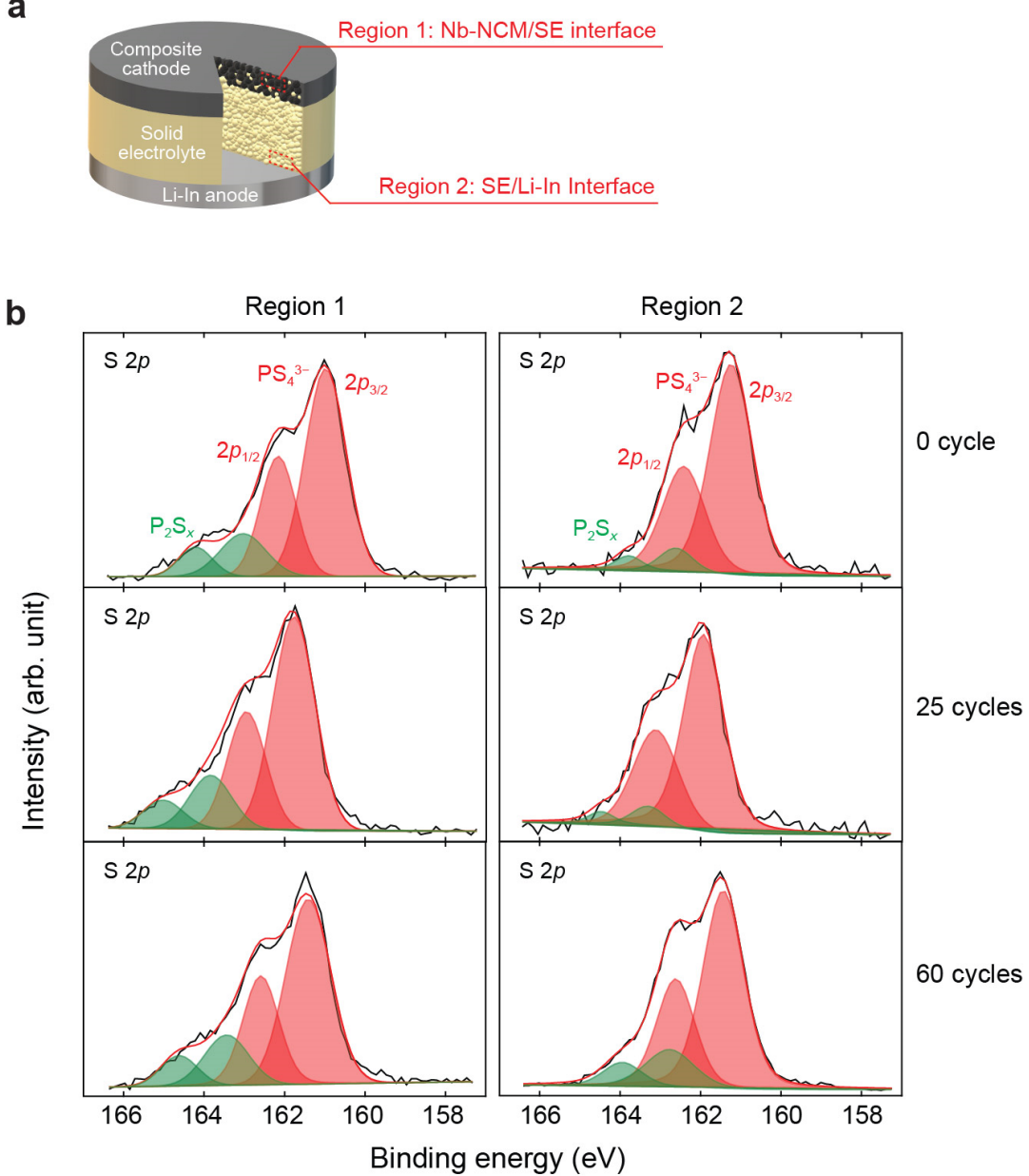

Figure S8. XPS analysis of UMA-based $\mathrm{Li}_{5.5} \mathrm{PS}_{4.5} \mathrm{Cl}_{1.5} \mathrm{SE}$ in an ASSB cell (Nb-NCM/Li ${ }_{5.5} \mathrm{PS}_{4.5} \mathrm{Cl}_{1.5} / \mathrm{Li}-\mathrm{In}$ cell; see Figure S7) before cycling ( 0 cycle), after 25 cycles and after 60 cycles. (a) A schematic illustration of a cell structure. The red rectangle in a schematic illustration indicates a point corresponding each XPS sampling region. (b) Ex-situ S $2 p$ XPS spectra of a cell during the charge/discharge cycles. In both regions, the $\mathrm{S} 2 p$ spectrum of SE is composed of two components. Similar to the literature, ${ }^{10,11}$ a major (red) doublet peak corresponds to $\mathrm{PS}_{4}{ }^{3-}$. A small peak (green) at higher binding energy can be assigned as polysulfide $\left(\mathrm{P}_{2} \mathrm{~S}_{x}\right.$ with $\left.x>5\right)$. We note that the partial formation of polysulfide $\mathrm{S} 2 p$ is consistently detected before and after cycling, as in the literature. ${ }^{12,13}$ Overall, the $\mathrm{S} 2 p$ doublet peaks were observed to remain almost unchanged after 60 cycles. 
a

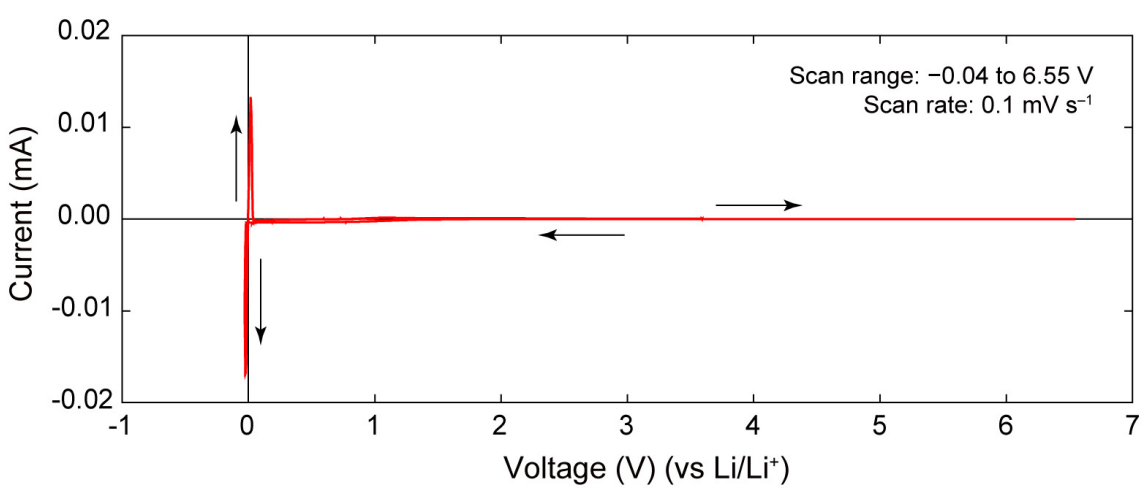

b

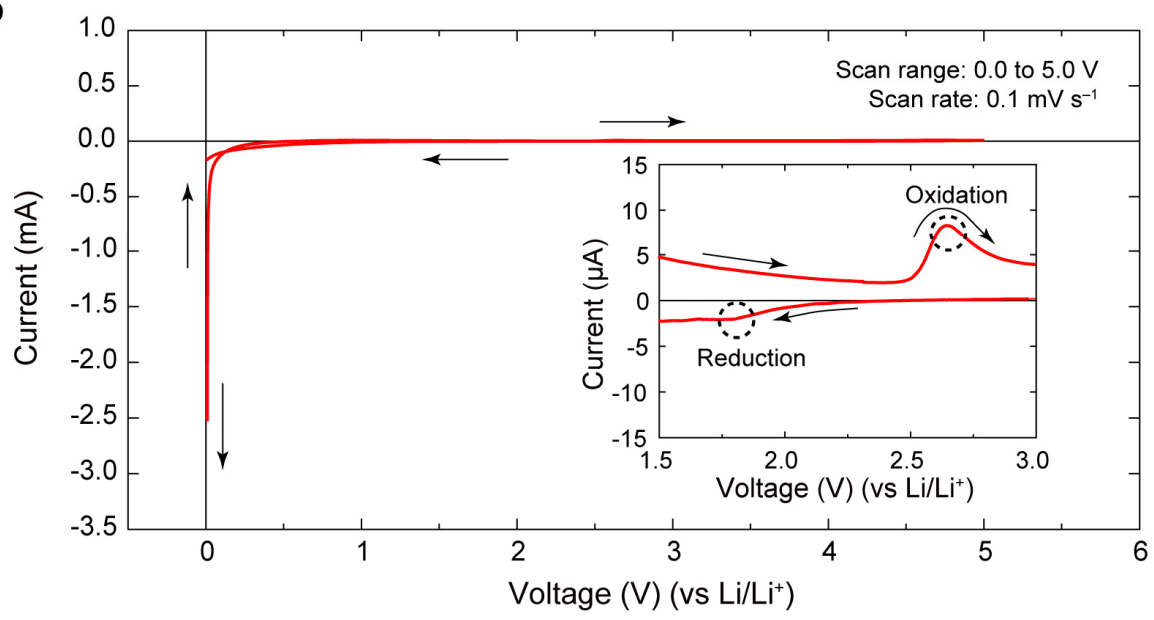

Figure S9. Cyclic voltammogram (CV) of UMA-based $\mathrm{Li}_{5.5} \mathrm{PS}_{4.5} \mathrm{Cl}_{1.5}$ using asymmetric semi-blocking cells of (a) typical setup ( $\mathrm{Li} / \mathrm{Li}{ }_{5.5} \mathrm{PS}_{4.5} \mathrm{Cl}_{1.5} /$ Stainless-Steel) and (b) rigorous setup $\left(\mathrm{Li} / \mathrm{Li}_{5.5} \mathrm{PS}_{4.5} \mathrm{Cl}_{1.5} / \mathrm{Li}_{5.5} \mathrm{PS}_{4.5} \mathrm{Cl}_{1.5}\right.$-Carbon/Pt). All experiments were conducted at a scan rate of 0.1 $\mathrm{mV} \mathrm{s}^{-1}$. 


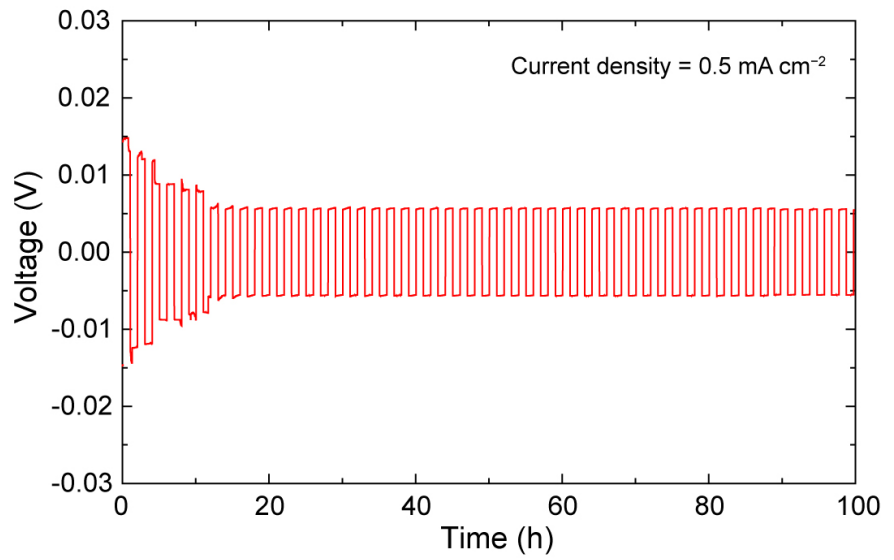

Figure S10. Voltage profile of galvanostatic Li plating-stripping on a symmetric cell

$\left(\mathrm{Li} / \mathrm{Li}_{5.5} \mathrm{PS}_{4.5} \mathrm{Cl}_{1.5} / \mathrm{Li}\right)$ over $100 \mathrm{~h}$. This cell was cycled at a current density of $0.5 \mathrm{~mA} \mathrm{~cm}{ }^{-2}$ and capacity of $0.5 \mathrm{mAh} \mathrm{cm}^{-2}$. 
Table S1. Detailed crystallographic information of $\mathrm{Li}_{7-x} \mathrm{PS}_{6-x} \mathrm{Cl}_{x}$ with different $\mathrm{Cl}$ content obtained from Rietveld refinement. Values in parentheses indicate the lattice parameter. $B_{\text {eq }}$ is the isotropic temperature factor.

\begin{tabular}{|c|c|c|c|c|c|c|c|}
\hline \multirow{2}{*}{ Materials } & \multirow{2}{*}{ Atom } & \multirow{2}{*}{ Site } & \multicolumn{3}{|c|}{ Fractional atomic coordinates } & \multirow{2}{*}{ Occupancy } & \multirow{2}{*}{$B_{\text {eq }}\left(\AA^{2}\right)$} \\
\hline & & & $x$ & $y$ & $z$ & & \\
\hline \multirow{7}{*}{$\begin{array}{c}x=0.50 \\
(9.9793 \AA)\end{array}$} & $\mathrm{Li}$ & $48 h$ & 0.1760 & 0.1760 & 0.0179 & 0.5410 & 4.0000 \\
\hline & $\mathrm{P}$ & $4 b$ & 0.5000 & 0.5000 & 0.5000 & 1.0000 & 1.6760 \\
\hline & $\mathrm{S}$ & $16 e$ & 0.6207 & 0.6207 & 0.6207 & 1.0000 & 2.1570 \\
\hline & $\mathrm{S}$ & \multirow{2}{*}{$4 c$} & \multirow{2}{*}{0.2500} & \multirow{2}{*}{0.2500} & \multirow{2}{*}{0.2500} & 0.8910 & 2.1780 \\
\hline & $\mathrm{Cl}$ & & & & & 0.1090 & 2.1780 \\
\hline & $\mathrm{S}$ & \multirow{2}{*}{$4 a$} & \multirow{2}{*}{0.0000} & \multirow{2}{*}{0.0000} & \multirow{2}{*}{0.0000} & 0.6670 & 2.3160 \\
\hline & $\mathrm{Cl}$ & & & & & 0.3330 & 2.3160 \\
\hline \multirow{7}{*}{$\begin{array}{c}x=1.00 \\
(9.8565 \AA)\end{array}$} & $\mathrm{Li}$ & $48 h$ & 0.1726 & 0.1726 & 0.0195 & 0.5000 & 4.0000 \\
\hline & $\mathrm{P}$ & $4 b$ & 0.5000 & 0.5000 & 0.5000 & 1.0000 & 1.2770 \\
\hline & $\mathrm{S}$ & $16 e$ & 0.6199 & 0.6199 & 0.6199 & 1.0000 & 2.4140 \\
\hline & $\mathrm{S}$ & \multirow{2}{*}{$4 c$} & \multirow{2}{*}{0.2500} & \multirow{2}{*}{0.2500} & \multirow{2}{*}{0.2500} & 0.5500 & 2.2790 \\
\hline & $\mathrm{Cl}$ & & & & & 0.4500 & 2.2790 \\
\hline & $\mathrm{S}$ & \multirow{2}{*}{$4 a$} & \multirow{2}{*}{0.0000} & \multirow{2}{*}{0.0000} & \multirow{2}{*}{0.0000} & 0.4700 & 2.2800 \\
\hline & $\mathrm{Cl}$ & & & & & 0.5300 & 2.2800 \\
\hline \multirow{7}{*}{$\begin{array}{c}x=1.50 \\
(9.7557 \AA)\end{array}$} & $\mathrm{Li}$ & $48 h$ & 0.1727 & 0.1727 & 0.0183 & 0.4580 & 4.0000 \\
\hline & $\mathrm{P}$ & $4 b$ & 0.5000 & 0.5000 & 0.5000 & 1.0000 & 1.6520 \\
\hline & $\mathrm{S}$ & $16 e$ & 0.6197 & 0.6197 & 0.6197 & 1.0000 & 2.9810 \\
\hline & S & \multirow{2}{*}{$4 c$} & \multirow{2}{*}{0.2500} & \multirow{2}{*}{0.2500} & \multirow{2}{*}{0.2500} & 0.2804 & 2.2250 \\
\hline & $\mathrm{Cl}$ & & & & & 0.7196 & 2.2250 \\
\hline & $\mathrm{S}$ & \multirow{2}{*}{$4 a$} & 00000 & 00000 & 00000 & 0.2297 & 2.2140 \\
\hline & $\mathrm{Cl}$ & & & & & 0.7703 & 2.2140 \\
\hline & $\overline{\mathrm{Li}}$ & $48 h$ & 0.1705 & 0.1705 & 0.0171 & 0.4375 & 4.0000 \\
\hline & $\mathrm{P}$ & $4 b$ & 0.5000 & 0.5000 & 0.5000 & 1.0000 & 1.4180 \\
\hline & $\mathrm{S}$ & $16 e$ & 0.6197 & 0.6197 & 0.6197 & 1.0000 & 2.8120 \\
\hline $\begin{array}{c}x=1.13 \\
(97034 \AA)\end{array}$ & $\mathrm{S}$ & $4 c$ & 02500 & 02500 & 02500 & 0.1741 & 2.2340 \\
\hline & $\mathrm{Cl}$ & $4 c$ & & & 0.2500 & 0.8259 & 2.2340 \\
\hline & $\mathrm{S}$ & $4 a$ & 0.0000 & 0.0000 & 0.0000 & 0.1945 & 2.1970 \\
\hline & $\mathrm{Cl}$ & $4 a$ & 0.0000 & 0.0000 & 0.0000 & 0.8055 & 2.1970 \\
\hline
\end{tabular}


Table S2. Comparison of the specific energy density in this work compared to the previously reported sulfide-based ASSBs at room temperature $\left(25^{\circ} \mathrm{C}\right)$.

\begin{tabular}{|c|c|c|c|c|c|c|}
\hline \multirow[b]{2}{*}{ Reference } & \multirow[b]{2}{*}{ Type } & \multirow[b]{2}{*}{$\begin{array}{l}\text { Cathode active } \\
\text { material }\end{array}$} & \multirow[b]{2}{*}{ Main SE } & \multirow[b]{2}{*}{$\begin{array}{l}\text { Anode active } \\
\text { material }\end{array}$} & \multicolumn{2}{|c|}{ Specific energy density $\left(\mathrm{Wh} \mathrm{kg}^{-1}\right)$} \\
\hline & & & & & $\begin{array}{l}\text { Based on mass of } \\
\text { active material }\end{array}$ & $\begin{array}{c}\text { Based on total mass } \\
\text { of cell }\end{array}$ \\
\hline 14 & Sheet & $\mathrm{LiCoO}_{2}$ & $\mathrm{Li}_{10} \mathrm{GeP}_{2} \mathrm{~S}_{12}$ & $\mathrm{Li}_{4} \mathrm{Ti}_{5} \mathrm{O}_{12}$ & - & 44 \\
\hline 15 & Sheet & $\mathrm{LiNi}_{1 / 3} \mathrm{Co}_{1 / 3} \mathrm{Mn}_{1 / 3} \mathrm{O}_{2}$ & $\mathrm{Li}_{3} \mathrm{PS}_{4}$ & $\mathrm{Si}$ & - & 212 \\
\hline 16 & Sheet & $\mathrm{LiNi}_{1 / 3} \mathrm{Co}_{1 / 3} \mathrm{Mn}_{1 / 3} \mathrm{O}_{2}$ & $\mathrm{Li}_{3} \mathrm{PS}_{4}$ & Graphite & - & 155 \\
\hline 17 & Pellet & $\mathrm{LiCoO}_{2}$ & $\mathrm{Li}_{10} \mathrm{GeP}_{2} \mathrm{~S}_{12}$ & $\mathrm{Li}_{4} \mathrm{Ti}_{5} \mathrm{O}_{12}$ & 297.7 & 16.4 \\
\hline This work & Pellet & $\mathrm{LiNi}_{0.6} \mathrm{Co}_{0.2} \mathrm{Mn}_{0.2} \mathrm{O}_{2}$ & $\mathrm{Li}_{5.5} \mathrm{PS}_{4.5} \mathrm{Cl}_{1.5}$ & Li-In & 319.9 & 37.6 \\
\hline
\end{tabular}




\section{REFERENCES}

(1) Lopez-Rubio, A.; Flanagan, B. M.; Gilbert, E. P.; Gidley, M. J. A novel approach for calculating starch crystallinity and its correlation with double helix content: a combined XRD and NMR study. Biopolymers 2008, 89, 761-768.

(2) Kresse, G.; Hafner, J. Ab initio molecular dynamics for liquid metals. Phys. Rev. B 1993, 47, 558-561.

(3) Perdew, J. P.; Burke, K.; Ernzerhof, M. Generalized gradient approximation made simple. Phys. Rev. Lett. 1996, 77, 3865-3868.

(4) Nosé, S. A unified formulation of the constant temperature molecular dynamics methods. J. Chem. Phys. 1984, $81,511-519$.

(5) Ong, S. P.; Richards, W. D.; Jain, A.; Hautier, G.; Kocher, M.; Cholia, S.; Gunter, D.; Chevrier, V. L.; Persson, K. A.; Ceder, G. Python materials genomics (pymatgen): A robust, open-source python library for materials analysis. Comp. Mater. Sci. 2013, 68, 314-319.

(6) Kato, A.; Yamamoto, M.; Sakuda, A.; Hayashi, A.; Tatsumisago, M. Mechanical properties of $\mathrm{Li}_{2} \mathrm{~S}_{-} \mathrm{P}_{2} \mathrm{~S}_{5}$ glasses with lithium halides and application in all-solid-state batteries. ACS Appl. Energy Mater. 2018, 1, $1002-1007$.

(7) Choi, S.; Jeon, M.; Jung, W. D.; Yang, S.; Park, S.; Ji, H.-I.; Lee, J.-H.; Kim, B.-K.; Sang, B.-I.; Kim, H. Robust solid-state interface with a deformable glass interlayer in sulfide-based all-solid-state batteries. Solid State Ionics 2020, 346, 115217.

(8) Hwang, A.; Ma, Y.; Cao, Y.; Li, Q.; Wang, L.; Cheng, X.; Zuo, P.; Du, C.; Gao, Y.; Yin, G. Fabrication and electrochemical properties of $\mathrm{Li}_{4} \mathrm{Ti}_{5} \mathrm{O}_{12} @ \mathrm{Li}_{6} \mathrm{PS}_{5} \mathrm{Cl}$ for all-solid-state lithium batteries using simple mechanical method. Int. J. Electrochem. Sci. 2017, 12, 7795-7806.

(9) Wang, S.; Zhang, Y.; Zhang, X.; Liu, T.; Lin, Y.-H.; Shen, Y.; Li, L.; Nan, C.-W. High-conductivity argyrodite $\mathrm{Li}_{6} \mathrm{PS}_{5} \mathrm{Cl}$ solid electrolytes prepared via optimized sintering processes for all-solid-state lihtiumsulfur batteries. ACS Appl. Mater. Interfaces 2018, 10, 42279-42285.

(10) Ohno, S.; Koerver, R.; Dewald, G.; Rosenbach, C.; Titscher, P.; Stechermeier, D.; Kwade, A.; Janek, J. Observation of chemomechanical failure and the influence of cutoff potentials in all-solid-state Li-S batteries. Chem. Mater. 2019, 31, 2930-2940. 
(11) Kim, A.-Y.; Strauss, F.; Bartsch, T.; Teo, J. H.; Hatsukade, T.; Mazilkin, A.; Janek, J.; Hartmann, P.; Brezesinski, T. Stabilizing effect of a hybrid surface coating on a Ni-rich NCM cathode material in all-solidstate batteries. Chem. Mater. 2019, 31, 9664-9672.

(12) Hakari, T.; Deguchi, M.; Mitsuhara, K.; Ohta, T.; Saito, K.; Orikasa, Y.; Uchimoto, Y.; Kowada, Y.; Hayashi, A.; Tatsumisago, M. Structural and electronic-state changes of a sulfide solid electrolyte during the Li deinsertion-insertion processes. Chem. Mater. 2017, 29, 4768-4774.

(13) Zhang, J.; Zheng, C.; Li, L.; Xia, Y.; Huang, H.; Gan, Y.; Liang, C.; He, X.; Tao, X.; Zhang, W. Unraveling the intra and intercycle interfacial evolution of $\mathrm{Li}_{6} \mathrm{PS}_{5} \mathrm{Cl}$-based all-solid-state lithium batteries. Adv. Energy Mater. 2020, 10, 1903311.

(14) Nam, Y. J.; Cho, S.-J.; Oh, D. Y.; Lim, J.-M.; Kim, S. Y.; Song, J. H.; Lee, Y.-G.; Lee, S.-Y.; Jung, Y. S. Bendable and thin sulfide solid electrolyte film: a new electrolyte opportunity for free-standing and stackable high-energy all-solid-state lithium-ion batteries. Nano Lett. 2015, 15, 3317-3323.

(15) Yamamoto, M.; Terauchi, Y.; Sakuda, A.; Takahashi, M. Slurry mixing for fabricating silicon-composite electrodes in all-solid-state batteries with high areal capacity and cycling stability. J. Power Sources $\mathbf{2 0 1 8 ,}$ $402,506-512$.

(16) Sakuda, A.; Kuratani, K.; Yamamoto, M.; Takahashi, M.; Takeuchi, T.; Kobayashi, H. All-solid-state battery electrode sheets prepared by a slurry coating process. J. Electrochem. Soc. 2017, 164, A2474-A2478.

(17) Kato, Y.; Hori, S.; Saito, T.; Suzuki, K.; Hirayama, M.; Mitsui, A.; Yonemura, M.; Iba, H.; Kanno, R. Highpower all-solid-state batteries using sulfide superionic conductors. Nat. Energy 2016, 1, 16030. 